\title{
Genetic susceptibility to advanced retinopathy of prematurity (ROP)
}

\author{
Barkur S Shastry
}

\begin{abstract}
Retinopathy of prematurity (ROP) is a vascular vitreoretinopathy that affects infants with short gestational age and low birth-weight. The condition is a multifactorial disease and is clinically similar to familial exudative vitreoretinopathy (FEVR), which is a bilateral hereditary eye disorder affecting full-term infants. Both of them are characterized by the abnormal vessel growth in the vitreous that can lead to vitreoretinal traction, retinal detachment and other complications resulting in blindness. Despite the recent advances in diagnosis and treatment, ROP remains a major cause of childhood blindness in developed countries. The etiology of pathogenesis of advanced ROP is currently unknown. In the past, many causative factors such as length of time exposed to supplemental oxygen, excessive ambient light exposure and hypoxia have been suggested but evidence for these as independent risk factors in recent years is not compelling. It is not clear why ROP in a subset of infants with low birth-weight progresses to a severe stage (retinal detachment) despite timely intervention whereas in other infants with similar clinical characteristics ROP regresses spontaneously. Recent research with candidate gene approach, higher concordance rate in monozygotic twins and other clinical and experimental animal studies, suggest a strong genetic predisposition to ROP besides environmental factors such as prematurity. Three genes, which are involved in the Wnt signaling pathway, are mutated in both FEVR and in a small percentage of ROP disorder. However, none of the genetic factors identified thus far in ROP, account for a substantial number of patient population. Future studies involving genomics, bioinformatics and proteomics may provide a better understanding of the pathophysiology and management of ROP.
\end{abstract}

\section{Introduction}

Retinopathy of prematurity (ROP), also known as retrolental fibroplasia, is a well-known visual impairment in premature children. It is a disease of developing retinal blood vessels, which is seen predominantly in infants of short gestational age and low birth-weight. The condition is a multifactorial disease and is clinically similar to familial exudative vitreoretinopathy (FEVR), which is a bilateral hereditary eye disorder affecting full-term infant. While FEVR is a genetically heterogeneous disorder and is inherited as an $\mathrm{X}$-linked recessive, autosomal dominant $(\mathrm{AD})$ and autosomal recessive (AR) mode [1], ROP is a non-familial disorder. Both of these disorders cause blindness in young children and are characterized in the early stage by the premature arrest of the vascularization of the peripheral retina (Fig. 1) that can lead to extra-retinal fibrovascular proliferation, vitreal

Correspondence: shastry@oakland.edu

Department of Biological Sciences, Oakland University, Rochester, MI, USA traction, retinal fold and retinal detachment resulting in blindness. Both of them carry a high financial cost for the community and the individual by affecting the normal motor, language, conceptual and social development of the child. It is estimated that the overall incidence rate of the condition is about $68 \%$ among infants born with birth weight less than $1251 \mathrm{~g}$ and $98 \%$ among children born with birth weight less than $750 \mathrm{~g}$ [2].

\section{Pathogenesis}

The International Classification of ROP divides the development of the disorder into 5 stages. In the early stages, ROP is characterized by an incomplete vascularization of the retina (Fig. 1 panel A), with a sharply demarcated boundary between vascularized and avascularized retina (stage 1). This can progress to an elevated ridge (Fig. 1 panel B) that consists of mesenchymal tissue (stage 2). In more advanced stages of the disease, extra-retinal fibrovascular proliferation occurs (Fig. 1 panel C) on the posterior border of the ridge (stage 3) 

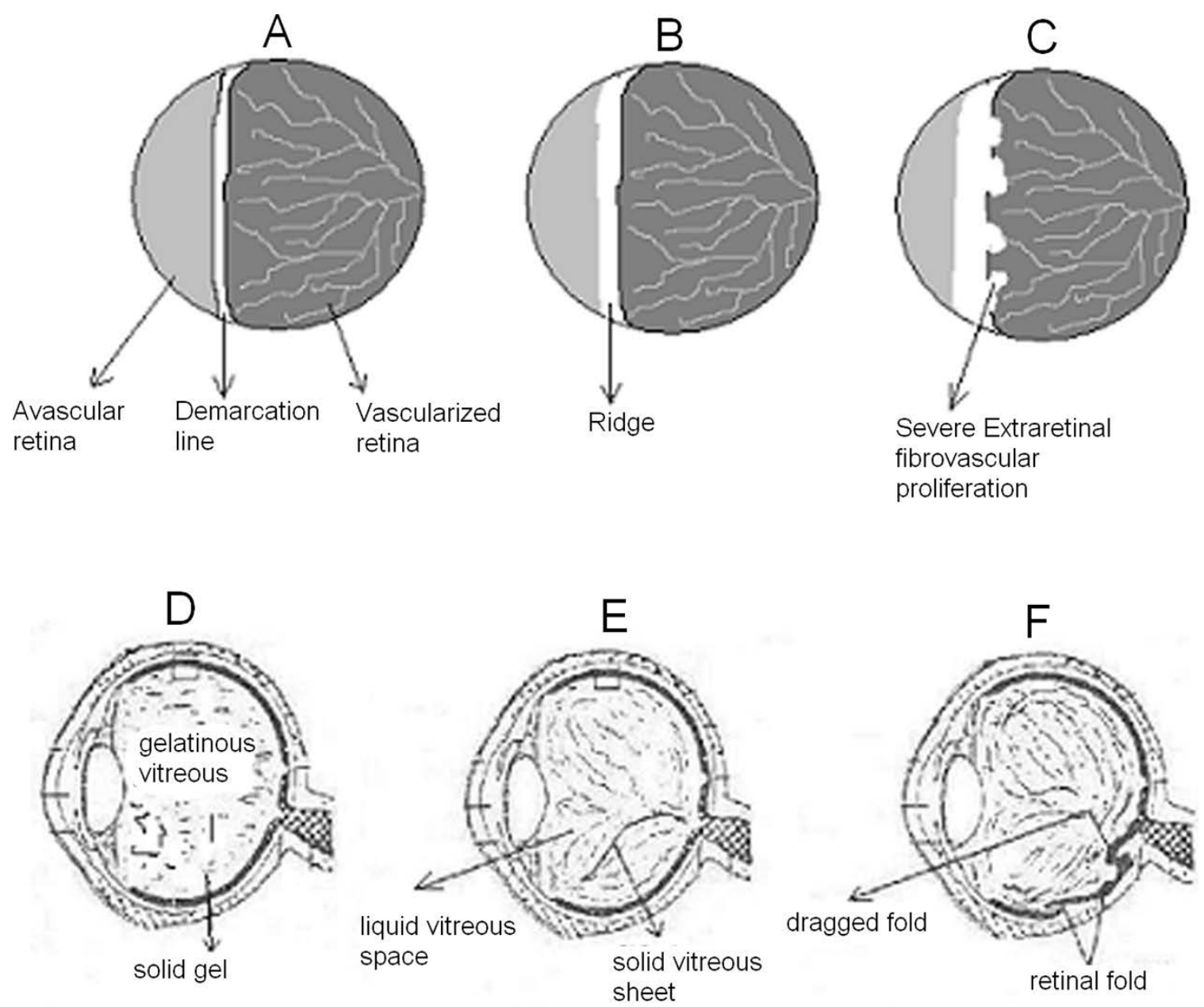

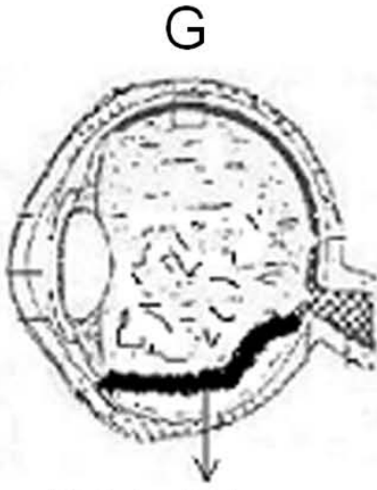

Partial retinal detachment

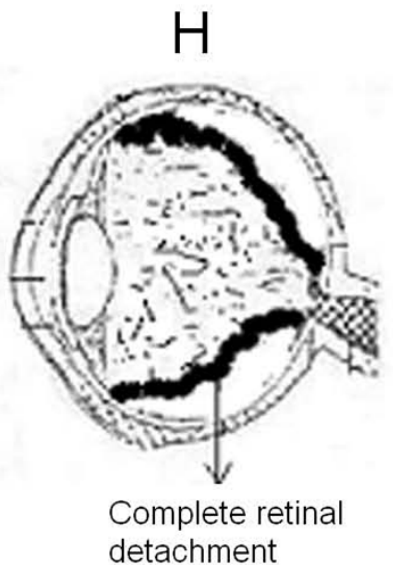

Figure 1 A schematic illustration of some of the abnormalities associated with advanced ROP. In the early stages, ROP is characterized by an incomplete vascularization of the peripheral retina (panel A), with a sharply demarcated boundary between vascularized and avascularized retina (stage 1). This can progress to an elevated ridge (panel B) that consists of mesenchymal tissue (stage 2). In more advanced stages of the disease, extra-retinal fibrovascular proliferation occurs (panel C) on the posterior border of the ridge (stage 3). In addition to the abnormal vascularization, the normal gelatinous vitreous (panel D) becomes partially liquefied (panel E). While spontaneous regression often occurs, an organization and contraction of vitreous collagen can take place (panel E) which can lead to a retinal fold (panel F) causing partial (panel G) or total retinal detachment (panel $\mathrm{H}$ ) that represent stages 4 and 5 respectively. 
and may be associated with dilated and tortuous retinal vessels (stage $3+$ or threshold). In addition to the abnormal vascularization, the normal gelatinous vitreous (Fig. 1 panel D) becomes partially liquefied (Fig. 1 panel E). While spontaneous regression often occurs, an organization and contraction of vitreous collagen can take place (Fig. 1 panels D, E and F) leading to partial (stage 4) or total (stage 5) retinal detachment (Fig. 1 panels G and $\mathrm{H}$ respectively). In advanced ROP, abnormal vessels grow out of the retina into the vitreous. This abnormal growth can lead to hemorrhage, fibrovascular changes, vitreoretinal traction, and retinal detachment (Fig. 1) and ultimately results in blindness.

Additionally, other complications of ROP or current treatment have also been reported. This includes retinal fold, dragging of the macula, glaucoma, cataract and strabismus. It is a life time disease. The condition in some children may appear milder and may not require treatment during the active stages or it may be regressed with little or no loss of visual function. However, these same children may later develop visual impairments from progressive retinal epithelial changes $[3,4]$. This type of childhood blindness has severe consequences that may result in less opportunity for education, employment and earning potential. It can also affect socioeconomic development.

\section{Genetic risk factors}

Despite advances in our understanding and management of ROP, it remains a leading cause of blindness in children in developed countries. Although many causative factors such as excessive light exposure, length of time exposed to supplemental oxygen and hypoxia have been suggested $[5,6]$, the etiology of pathogenesis of advanced ROP is not understood. However, low birth-weight and short gestational age have been consistently shown to be associated with ROP. It is unclear why ROP in a subset of infants with low birth-weight progresses to a severe stage despite timely intervention whereas in other infants with similar clinical characteristics, ROP regresses spontaneously. Molecular genetic studies of FEVR have identified four causative genes to date (NDP, FZD4, LRP5 and TSPAN12) which when mutated cause X-linked, AD and AR FEVR (also some sporadic cases). All of these genes are involved in the beta-catenin mediated Wnt signaling pathway (see below) that controls the development of the retinal vasculature [7-9]. Because of mutations in these genes, norrin-FZD4-LRP5-TSPAN12 signaling pathway may become defective and that may produce abnormal vascularization giving rise to FEVR pathology. Interestingly, using a candidate gene approach, it has been shown that at least three of the four FEVR genes (NDP, FZD4 and LRP5) are also mutated in a small percentage (3-11\%) of severe ROP patients [[10-19] and Hiraoka etal. personal communication]. This genetic predisposition is further supported by the recent twin studies [20], race [21] and strain-dependent differences in oxygen induced ROP in the inbred rats [22-24]. Because three of the four FEVR genes are mutated in advanced ROP and all four FEVR genes are involved in Wnt signaling pathway, the above genetic explanation of ROP supports a role for the Wnt signaling pathway in the development of severe ROP that can be of a therapeutic value in the future. Because it is the same pathway that appears to be defective in both of these disorders (ROP and FEVR), their clinical similarities can be explained. Considering all the available data to date, it appears that NDP, FZD4 and LRP5 gene polymorphisms can account for about $10-12 \%$ of ROP and this prevalence may be correlated with ethnic differences. However, the NDP, FZD4 and LRP5 genes are not the major genes independently accounting for a significant portion of ROP patients. This suggests that mutations in other genes involved in retinal development, angiogenesis and Wnt signaling pathway could also be associated with severe ROP in a small proportion of patients.

\section{Association of other genes with ROP}

The blinding complication of ROP is strongly associated with the development of retinal neovascularization. In normal instances, the vascularization of the human retina is largely complete by the $4^{\text {th }}$ month of gestation but peripheral retinal vascularization will not be in place until the fetus is near term. ROP pathogenesis occurs in two phases: the vascular attenuation phase (phase I) and the fibrovascular proliferative phase (phase II). In phase I, hyperoxia (because of supplemental oxygen) causes cessation of normal retinal vascularization and in phase II, hypoxia renews vascularization. In both of these cases vascular endothelial growth factor (VEGF) plays a major role $[25,26]$ and depending on local retinal responses, the effect can be normal or abnormal vascularization. Several case control studies have also confirmed the association of VEGF single nucleotide polymorphisms (SNPs) with diseases as diverse as breast cancer, oral cancer, Alzheimer disease and kidney disease. It has also been reported that increased expression of VEGF gene is associated with both avascular retina and intravitreous neovascularization [27] in a model of ROP. Many polymorphisms of VEGF gene have been described. Some of them are in the promoter and $5^{\prime}$-untranslated region but some of them are in the 3 '-untranslated region (3'-UTR). Several polymorphisms within the VEGF gene are correlated with variation in VEGF protein production [28]. For instance, it was reported previously [29] that the CC genotype of C936T polymorphism in the 3'-UTR of VEGF gene was associated with an increase in the VEGF level in the peripheral blood circulation as compared with CT and TT genotypes. In support of the 
VEGF gene involvement in ROP, some studies have shown an association of VEGF gene polymorphism and ROP $[30,31]$ but these results are not replicated by other studies [32-36].

Additionally, it has also been reported that a prolonged period of low levels of insulin-like growth factorI (IGF-I) may predict the development of ROP and other complications of premature birth [37]. Infants with higher IGF-I do not develop ROP and exhibit better vascular development. This growth factor (IGF-I) is an intrauterine growth factor and is expressed in retinal cells. Several studies also suggest that it is essential for vascular development of the eye in the postnatal period. These results were supported by IGF-I knockout mice that developed abnormal retinal vascular growth. Because prematurity is one of the factors that contributes to ROP and the IGF-I level is determined by the IGF-I receptor (IGF-I R) and the most prevalent polymorphism of IGF-I R (3174 G to A) exhibited low levels of free plasma IGF-I, it is possible that it may have a role in ROP. However, studies [38,39] do not support the association of this polymorphism and the risk of advanced ROP in different populations. Similarly, angiotensin-converting enzyme gene polymorphism is found to be associated with ROP in Kuwaiti population [16] but not in the other population [40,41]. Additionally, suggestive association has been reported between AGTR1 (encodes angiotensin II type I receptor), IHH (Indian Hedgehog), TBX-5 (T-box 5), glycoprotein Ib alpha polypeptide (GP1BA) and cholesterol ester transfer protein (CETP) and development of ROP [42]. However, these results need to be confirmed in a larger and independent population.

\section{Relationship between FEVR and advanced ROP}

While it remains to be seen whether the recently reported fourth gene (TSPAN12) of FEVR is also involved in advanced ROP patients, the above studies demonstrated that mutations are present in either small percentage of ROP patients or limited geographically to a specific ethnic population. Although there are many questions such as accuracy of diagnosis and small percentage of ROP patients harboring mutations in FEVR genes that need to be addressed before any conclusion can be drawn, based on the studies conducted from around the world involving different ethnic background patients, it is possible that the advanced ROP could be in fact a sporadic FEVR and the prematurity is an environmental factor that simply speeds up the progression of the disease. Thus, it is conceivable that in ROP, gene abnormality coupled with postnatal physiological changes and various environmental factors (e.g. prematurity) may result in the development and progression of ROP that would ordinarily be suppressed in a full term infant with FEVR. Based on these assumptions we propose the following (Fig. 2), purely speculative, double-hit-working model to explain the development of advanced ROP in premature infants. In stage 4 - 5 ROP, de novo gene mutation coupled with environmental factors (e.g. prematurity) may lead to the progression and development of retinal detachment whereas prematurity alone without gene mutation may lead to an early stage of ROP that may subsequently regress to a normal condition. On the other hand, inherited or de novo mutations without prematurity may result in familial and sporadic FEVR respectively, which develop during the first decade of life.

\section{Wnt signaling pathway}

The exact mechanism to explain how the mutant genes thus far identified cause incomplete vascularization of the retina in ROP is not known. However, mutations in the NDP, FZD4 and LRP5 genes in ROP and the finding that the same genes are also mutated in a morphologically similar disorder FEVR suggest that a similar mechanism may be involved in ROP and FEVR pathogenesis. Interestingly, as mentioned above, all the above four genes are involved in the Wnt signaling pathway. Therefore, the defective Wnt signaling pathway may be responsible for both FEVR and ROP pathogenesis. The Wnt signaling pathway (Fig. 3) is highly conserved and regulated among many species. It plays a key role in embryonic development including eye development. It was also shown that TSPAN12 is a component of the norrin -FZD4 - LRP5 - signaling complex and increases the levels of norrin-beta-catenin signaling but not Wntbeta-catenin signaling. The protein TSPAN 12 is a member of tetraspanin family and facilitates the formation of multimolecular membrane complexes. A series of experiments demonstrated that TSPAN 12 is required for the multimerization of FZD4. Recently, it has been reported that [43] a transcription factor called sox 17 is upregulated by norrin-FZD4-LRP5 signaling. This factor plays an important role in inducing the angiogenic program for retinal vascularization. Therefore, loss of or insufficient norrin-FZD4-LRP5 signaling (due to mutations) may cause defective vascular growth and that may lead to retinal hypovascularization, which is the predominant feature of both FEVR and ROP. Although there is no direct correlation between genotype and phenotype, alterations in highly conserved amino acids may affect the structure of receptors (FZD4 and LRP5), ligand (NDP), localization of mRNA or proteins or the quantity of proteins. This may inactivate or alter the pathway resulting in the inhibition or abnormality of vascular development in the above disorders. Mutations in the $5^{\prime}$ and $3^{\prime}$-untranslated regions (seen in NDP gene in ROP patients) may also alter the regulation of gene 


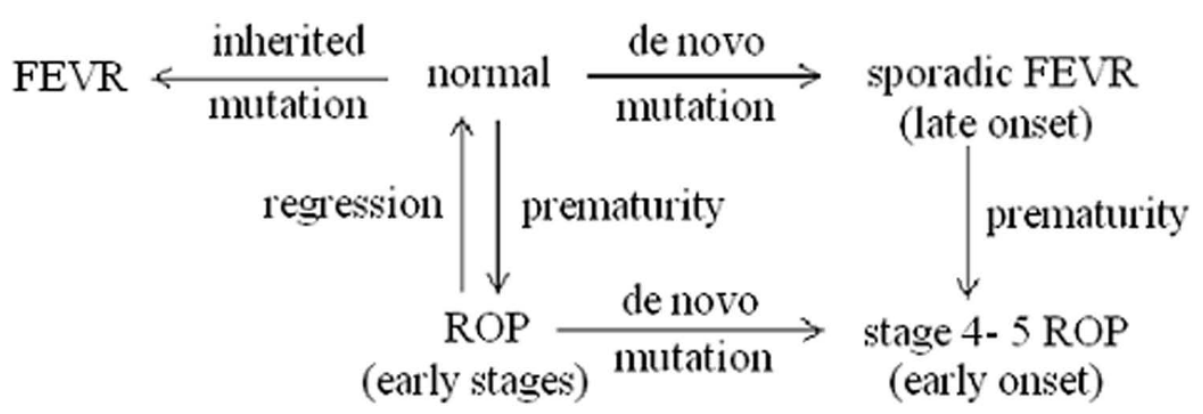

Figure 2 A highly hypothetical pathway that may lead to a cicatricial ROP and a morphologically similar disorder FEVR. De novo gene mutation coupled with environmental factors (e. g. prematurity) may lead to the progression and development of retinal detachment in stage 4 - 5 ROP whereas prematurity alone without gene mutation may lead to an early stage of ROP that may subsequently regress to a normal condition. On the other hand, inherited or de novo mutations without prematurity may result in familial and sporadic FEVR respectively, that develop during the first decade of life.

expression at the level of transcription, translation and mRNA stability. This may result in profound changes in the signal transduction (reduction in signaling) and hence produce changes in vascular development [44]. Mice lacking NDP, FZD4, TSPAN12 and LRP5 [45-48] further demonstrate the importance of wild-type genes in capillary maturation as well as this pathway in vasculogenesis and normal retinal development. However, these transgenic experiments must be interpreted with caution because, in many patients mutations in NDP, FZD4, LRP5 and TSPAN12 are missense whereas in mice models the above four genes are not expressed (null mutants). Further understanding of this pathway in ocular disease may lead to a novel therapeutic approach

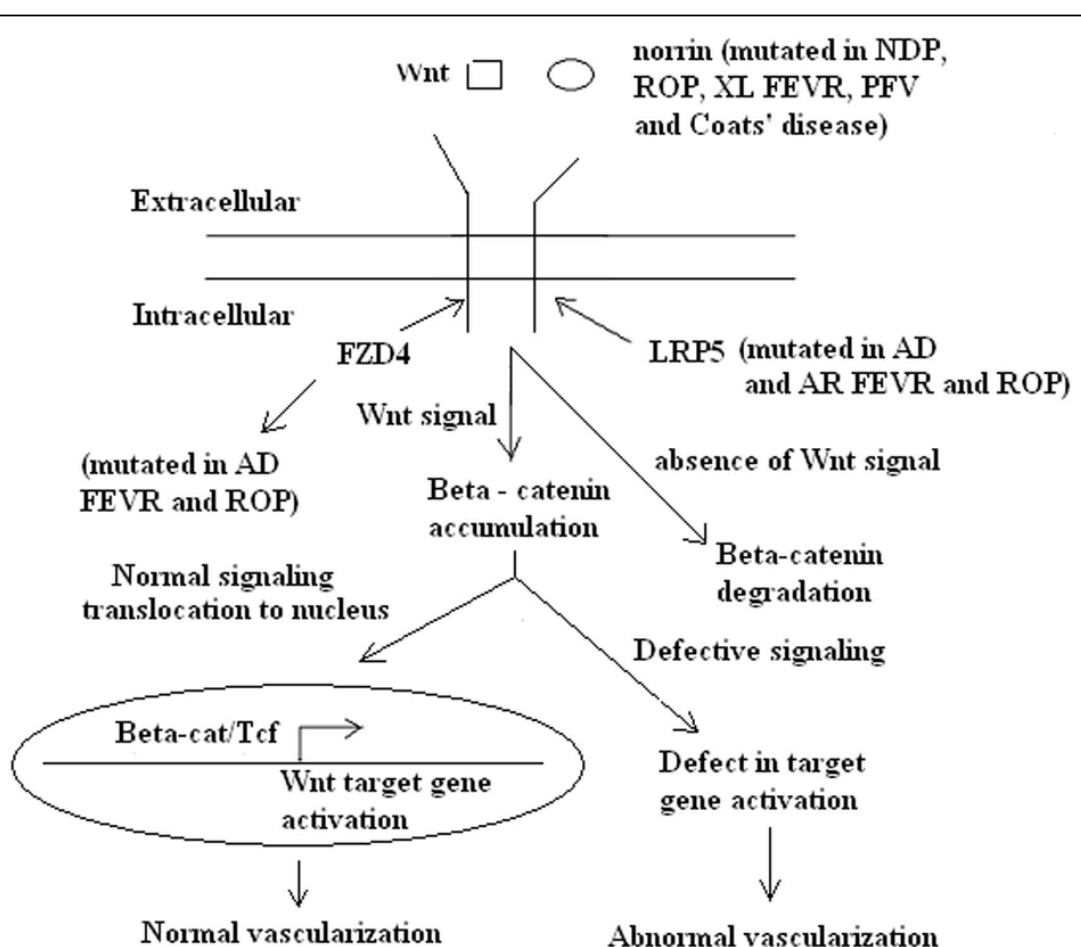

Figure 3 A schematic representation of the canonical Wnt signaling pathway. Norrin and Wnt act as ligands to bind FZD4 that interact with LRP5. In the absence of Wnt signaling, beta-catenin is phosphorylated and subjected to proteosomal degradation. In the presence of Wnt signaling, beta-catenin accumulates in the cytoplasm and enters the nucleus. Its subsequent interactions with a member of Tcf/Lef family activate the transcription of Wnt target genes. It was also shown that TSPAN12 is a component of the norrin-LRP5-FZD4 signaling complex and enhances the levels of norrin-beta-catenin signaling but not Wnt-beta-catenin signaling. Because of mutations in NDP, FZD4, LRP5 and TSPAN12 genes, abnormal signaling may occur which may result in defective Wnt target genes activation that may give rise to FEVR and ROP pathology. $A D=$ autosomal dominant; $A R=$ autosomal recessive; $X L=X$-linked recessive; $F E V R=$ familial exudative vitreoretinopathy; $R O P=$ retinopathy of prematurity; NDP = Norrie disease pseudoglioma. 
to treat or prevent these potentially blinding disorders in the future. However, large-scale studies involving different ethnic groups and direct experimental evidence to show that the same pathway is involved in ROP are needed to either confirm or refute the above suggestion.

\section{Conclusion}

ROP is a leading cause of blindness in children. It is unknown why some extremely premature babies develop severe ROP despite timely intervention whereas other babies with similar clinical characteristics do not progress to a severe stage. From the foregoing evidence it is clear that genetic factors in addition to prematurity or environmental factors play a major role in the development and progression of ROP. Identification of polymorphisms or mutations in genes is only the beginning and it may not solve all the problems. We need to consider bioinformatic and proteomic approaches at a given point in time [24]. A comparison of protein profile between normal and affected individuals throughout the course of the disease may provide a better diagnostic indicator. For instance, the mutated gene may be under the control of environmental factors such as oxygen exposure or prematurity and may not be expressed, over expressed or change the expression pattern of other genes. The proteomics approach directly addresses the status of genes. There are several promising biomarkers for the risk of ROP. For example, deamination of globin chains appears to be a promising marker [49]. Additionally, it is possible that ROP involves multiple genes rather than a single gene, each gene then contributing a small but additive effect resulting in the final phenotype. Thus, along with genomics, bioinformatics and proteomics approaches may ultimately provide a better management of ROP.

\section{Acknowledgements}

My apologies for those whose work or original publications could not be cited in this brief article because of the limitations to the number of references.

\section{Authors' contributions}

The manuscript was prepared by BSS.

\section{Competing interests}

The author declares that they have no competing interests.

Received: 25 June 2010 Accepted: 25 August 2010

Published: 25 August 2010

\section{References}

1. Shastry BS: Molecular genetics of Norrie disease, familial exudative vitreoretinopathy and retinopathy of prematurity. In In retinal degeneration: causes, diagnosis and treatment. Edited by: Catlin RB. New York: Nova Science Publishers Inc; 2009:89-106.

2. Good WV, Hardy RJ, Dobson V, Plamer EA, Phelps DL, Quintos M, Tung B: The incidence and course of retinopathy of prematurity: finding from the early treatment for retinopathy of prematurity study. Pediatrics 2005, 116:15-23.

3. Terasaki $\mathrm{H}$, Hirose T: Late - onset retinal detachment associated with regressed retinopathy of prematurity. Jpn J Ophthalmol 2003, 47:492-497

4. Gilbert WS, Quinn GE, Dobson V, Reynolds J, Hard RJ, Palmer EA: Partial retinal detachment at 3 months after threshold retinopathy of prematurity. Arch Ophthalmol 1996, 114:1085-1091.

5. Mechoulam H, Pierce EA: Retinopathy of prematurity. Am J Pharmacogenomics 2003, 3:261-277.

6. Wheatley CM, Dickinson JL, Mackey DA, Craig JE, Sale MM: Retinopathy of prematurity: recent advances in our understanding. $\mathrm{Br} J$ Ophthalmol 2002, 86:696-701.

7. Shastry BS: SNPs: impact on gene function and phenotype. Methods $\mathrm{Mol}$ Biol 2009, 578:3-22.

8. Nikopoulos K, Gilissen C, Hoischen A, van Nouhuys CE, Boonstra FN, Blokland EA, Arts P, Wieskamp N, Strom TM, Ayuso C, Tilanus MA, Bouwhuis S, Mukhopadhyay A, Scheffer H, Hoefsloot LH, Veltman JA, Cremers FP, Collin RW: Next generation sequencing of a $40 \mathrm{Mb}$ linkage interval reveals TSPAN 12 mutations in patients with familial exudative vitreoretinopathy. Am J Hum Genet 2010, 86:240-247.

9. Poulter JA, Ali M, Gilmour DF, Rice A, Kondo H, Hayashi K, Mackey DA, Kearns LS, Ruddle JB, Craig JE, Pierce EA, Downey LM, Mohamed MD, Markham AF, Inglehearn CF, Toomes C: Mutations in TSPAN 12 cause autosomal dominant familial exudative vitreoretinopathy. Am J Hum Genet 2010, 86:248-253.

10. Shastry BS, Pendergast D, Hartzer MK, Liu X, Trese MT: Identification of missense mutations in the Norrie disease gene associated with advanced retinopathy of prematurity. Arch Ophthalmol 1997, 115:651-656.

11. Dickinson JL, Sale MM, Passmore A, FitzGerald LM, Wheatley CM, Burdon KP, Craig JE, Tengtrisorn S, Carden SM, Maclean H, Mackey DA: Mutations in the NDP gene: contribution to Norrie disease, Familial Exudative Vitreoretinopathy and Retinopathy of Prematurity. Clin Exp Ophthalmol 2006, 34:682-688.

12. Mintz-Hittner HA, Miyashiro MJ, Knight-Nanan KM, O'Malley RE, Marlar RA: Vitreoretinal findings similar to retinopathy of prematurity in infants with compound heterozygous protein S deficiency. Ophthalmol 1999 106:1525-1530

13. Hiraoka M, Beristein DM, Trese MT, Shastry BS: Insertion and deletion mutations in the dinucleotide repeat region of the Norrie disease gene in patients with advanced retinopathy of prematurity. J Hum Genet 2001, 46:178-181.

14. Talks SJ, Ebenezer N, Hykin P, Adams G, Yang F, Schulenberg E, GregoryEvans $K$, Gregory-Evans Y: De novo mutation in the 5 '-regulatory region of the Norrie disease gene in retinopathy of prematurity. J Med Genet 2001, 38:e46.

15. Haider MZ, Devarajan LV, Al-Essa M, Kumar HA: C597A polymorphism in the Norrie disease gene is associated with advanced retinopathy of prematurity in Kuwaiti infants. J Biomed Sci 2002, 9:365-370.

16. Haider MZ, Devarajan LV, Al-Essa M, Kumar H: Angiotensin-converting enzyme gene insertion/deletion polymorphism in Kuwaiti children with retinopathy of prematurity. Biol Neonate 2002, 82:84-88.

17. Hutcheson KA, Paluru PC, Bernstein SL, Koh J, Rappaport EF, Leach RA, Young TL: Norrie disease gene sequence variants in an ethnically diverse population with retinopathy of prematurity. Mol Vis 2005, 11:501-508.

18. MacDonald MLE, Goldberg YP, MacFarlane J, Samuels ME, Trese MT, Shastry BS: Genetic variants of frizzled-4 gene in familial exudative vitreoretinopathy and advanced retinopathy of prematurity. Clin Genet 2005, 67:363-366.

19. Ells A, Guemsey DL, Wallace K, Zheng B, Vincer M, Allen A, Ingram A, Da Silva O, Siebert L, Sheidow T, Beis J, Robitaille JM: Severe retinopathy of prematurity associated with FZD4 mutations. Ophthalmic Genet 2010, 31:37-43.

20. Bizzarro MJ, Hussain N, Jonsson B, Feng R, Ment LR, Gruen JR, Zhang H Bhandari V: Genetic susceptibility to retinopathy of prematurity. Pediatrics 2006, 118:1858-1863.

21. Lang DM, Backledege J, Arnold RW: Is specific race a retinopathy prematurity risk factor. Arch Pediatr Adolesc Med 2005, 159:771-773.

22. Floyd BN, Leske DA, Wren SM, Mookadam M, Fautsch MP, Holmes JM: Difference between rat strains in models of retinopathy of prematurity. Mol Vis 2005, 11:524-530. 
23. Van Wijngaarden P, Coster DJ, Brereton HM, Gibbins IL, Williams KA: Straindependent differences in oxygen induced retinopathy of prematurity in the inbred rats. Invest Ophthalmol Vis Sci 2005, 46:1445-1452.

24. Holmstrom G, Van Wijngaarden P, Coster DJ, Williams KA: Genetic susceptibility to retinopathy of prematurity: the evidence from clinical and experimental animal studies. Br J Ophthalmol 2007, 97:1704-1708.

25. Pierce EA, Foley ED, Smith LEH: Regulation of Vascular endothelial growth factor by oxygen in a model of retinopathy of prematurity. Arch Ophthalmol 1996, 114:1219-1228.

26. Alon T, Hemo I, Itin A, Peer J, Stone J, Keshet E: Vascular endothelial growth factor acts as a survival factor for newly formed retinal vessels and has implications for retinopathy of prematurity. Nat Med 1995, 1:1024-1028.

27. Budd SJ, Hartnett ME: Increased angiogenic factors associated with peripheral avascular retina and intravitreous neovascularization: a model of retinopathy of prematurity. Arch Ophthalmol 2010, 128:589-595.

28. Watson CJ, Webb NJ, Bottomley MJ, Brenchley PE: Identification of polymorphisms within the vascular endothelial growth factor gene (VEGF): correlation with variation in VEGF protein production. Cytokine 2000, 12:1232-1235.

29. Renner W, Kotschan S, Hoffmann C, Obermayer-Pietsch B, Pilger E: A common $936 \mathrm{C} / \mathrm{T}$ mutation in the gene for vascular endothelial growth factor is associated with vascular endothelial growth factor plasma levels. J Vas Res 2000, 37:443-448.

30. Cooke RW, Drury JA, Mountford R, Clark D: Genetic polymorphisms and retinopathy of prematurity. Invest Ophthalmol Vis Sci 2004, 45:1712-1715.

31. Vannay AV, Dunai G, Banyasz I, Szabo M, Vamos R, Treszl A, Hajdu J, Tulassay T, Vasarhel YI: Association of genetic polymorphisms of vascular endothelial growth factor and risk of proliferative retinopathy of prematurity. Pediatr Res 2005, 57:396-398.

32. Shastry BS, Qu X: Lack of association of the VEGF gene promoter (-634 G to $C$ and $-460 C$ to $T$ ) polymorphism and the risk of advanced retinopathy of prematurity. Graefes Arch Clin Exp Ophthalmol 2007, 245:741-743.

33. Shastry BS: Lack of association of VEGF ( $-2578 \mathrm{C}$ to A) and ANG2 (-35 G to C) gene polymorphisms with the progression of retinopathy of prematurity. Graefes Arch Clin Exp Ophthalmol 2009, 247:859-860.

34. Kwinta P, Bik-Multanowski M, Mitkowska Z, Tomasik T, Pietrzyk JJ: The clinical role of vascular endothelial growth factor (VEGF) system in the pathogenesis of retinopathy of prematurity. Graefes Arch Clin Exp Ophthalmol 2008, 246:1467-1475.

35. Banyasz I, Bokodl G, Vannay A, Szebenl B, Treszl A, Vasarhelyi B, Tulassay T, Szabo A: Genetic polymorphisms of vascular endothelial growth factor and angiopoietin 2 in retinopathy of prematurity. Curr Eye Res 2006 31:685-690.

36. Dunai G, Vasarhelyi B, Szabo M, Hajdu J, Meszaros G, Tulassay T, Treszl A: Published genetic variants in retinopathy of prematurity: random forest analysis suggests a negligible contribution to risk and severity. Curr Eye Res 2008, 33:501-505.

37. Hellstrom A, Engstrom E, Hard AL, Albertsson-Wildand K, Carlsson B, Niklasson A, Lofqvist C, Svensson E, Holm S, Ewald U, Holmstrom G, Smith LE: Postnatal serum insulin-like growth factor - I deficiency is associated with retinopathy of prematurity and other complications of premature birth. Pediatrics 2003, 112:1016-1020.

38. Shastry BS: Assessment of the contribution of insulin-like growth factor -I receptor $3174 \mathrm{G}$ to $\mathrm{A}$ polymorphism to the progression of advanced retinopathy of prematurity. Eur J Ophthalmol 2007, 17:950-953.

39. Balogh A, Derzbach L, Vannay A, Vasarhelyi B: Lack of association between insulin-like growth factor - I receptor G3174A polymorphism and retinoapthy of prematurity. Graefes Arch Clin Exp Ophthalmol 2006, 244:1035-1038.

40. Spiegler J, Gilhaus A, Konig IR, Kattner E, Vochem M, Kuster H, Moller J, Muller D, Kribs A, Segerer H, Weig C, Nikischin W, Van der Wense A, Gebauer C, Herting E, Gopel W: Polymorphism in the renin-angiotensin system and outcome of very low birth weight infants. Neonatology 2009, 97:10-14.

41. John BR, Loggins J, Yanamandra K: Angiotensin converting enzyme insertion/deletion polymorphism does not alter sepsis outcome in ventilated very low birth weight infants. J Perinatol 2005, 25:205-209.
42. Mohamed S, Schaa K, Cooper ME, Ahrens E, Alvarado A, Colaizy T, Marazita ML, Murray JC, Dagle JM: Genetic contributions to the development of retinopathy of prematurity. Pediatr Res 2009, 65:193-197.

43. Ye X, Wang YS, Cahill H, Yu MZ, Badea TC, Smallwood PM, Peachey NS, Nathans J: Norrin, frizzled 4 and LRP5 signaling in endothelial cells controls a genetic program for retinal vascularization. Cell 2009, 139:285-298.

44. Qin M, Kondo H, Tahira T, Hayashi K: Moderate reduction of norrin signaling activity associated with the causative missense mutations identified in patients with familial exudative vitreoretinopathy. Hum Genet 2008, 122:615-623.

45. Berger W, Van de Pool D, Bachner D, Oerlemans F, Winkens H, Hameister $H$ Wieringa $\mathrm{B}$, Hendricks W, Ropers $\mathrm{H}-\mathrm{H}$ : An animal model for Norrie disease: gene targeting of mouse ND gene. Hum Mol Genet 1996, 5:51-59.

46. Wang Y, Huso D, Cahill H, Ruygo D, Nathans J: Progressive cerebellar, auditory, and esophageal dysfunction caused by targeted disruption of the frizzled- 4 gene. J Neurosci 2001, 21:4761-4771.

47. Xia CH, Liu H, Cheung D, Wang M, Cheng C, Du X, Chang B, Beutler B, Gong $X$ : A model for familial exudative vitreoretinopathy caused by LRP5 mutations. Hum Mol Genet 2008, 17:1605-1612.

48. Junge HJ, Yang S, Burton JR, Paes K, Shu X, French DM, Costa M, Rice DS, Ye W: TSPAN12 regulates retinal vascular development by promoting norrin but not Wnt induced FZD4/beta-catenin signaling. Cell 2009, 139:299-311.

49. Madan A, El-Ferzli G, Carlson SM, Whitin JC, Schilling J, Najmi A, Yu TT, Lau K, Dimmitt RA, Cohen HJ: A potential biomarker in the cord blood of preterm infants who develop retinopathy of prematurity. Pediatr Res 2007, 61:215-221.

doi:10.1186/1423-0127-17-69

Cite this article as: Shastry: Genetic susceptibility to advanced retinopathy of prematurity (ROP). Journal of Biomedical Science 2010 $17: 69$.

\section{Submit your next manuscript to BioMed Central and take full advantage of:}

- Convenient online submission

- Thorough peer review

- No space constraints or color figure charges

- Immediate publication on acceptance

- Inclusion in PubMed, CAS, Scopus and Google Scholar

- Research which is freely available for redistribution

Submit your manuscript at www.biomedcentral.com/submit
C) Biomed Central 